\title{
BMJ Open Support needs of carers making proxy healthcare decisions for people with dementia: a systematic review based on the Noblit and Hare meta-ethnographic synthesis of qualitative studies
}

\author{
Victoria Hodges (ㄷ) , Catherine Hynes, Samuel Lassa, Caroline Mitchell (ㅏ)
}

To cite: Hodges V, Hynes C, Lassa S, et al. Support needs of carers making proxy healthcare decisions for people with dementia: a systematic review based on the Noblit and Hare meta-ethnographic synthesis of qualitative studies. BMJ Open 2021;11:e052608. doi:10.1136/ bmjopen-2021-052608

- Prepublication history and additional supplemental material for this paper are available online. To view these files, please visit the journal online (http://dx.doi.org/10.1136/ bmjopen-2021-052608)

Received 22 April 2021 Accepted 29 September 2021

Check for updates

(C) Author(s) (or their employer(s)) 2021. Re-use permitted under CC BY-NC. No commercial re-use. See rights and permissions. Published by BMJ.

Academic Unit of Primary Medical Care, The University of Sheffield Faculty of Medicine Dentistry and Health, Sheffield, UK

Correspondence to

Dr Victoria Hodges;

v.hodges@sheffield.ac.uk

\section{ABSTRACT}

Background There are 50 million dementia sufferers worldwide. Decisions about healthcare often need to be made when the person with dementia lacks capacity to do so.

Understanding the support needs of carers acting as proxy healthcare decision-makers will be vital in improving the decision-making process for people with dementia and addressing the holistic needs of carers.

Objective The objective of this study was to review the existing literature on the support needs of carers acting as proxy healthcare decision-makers for people with dementia.

Design A qualitative systematic review protocol was published on PROSPERO. The Critical Appraisal Skills Programme checklist was used to appraise study quality. A meta-ethnographic synthesis was performed to develop third-order constructs.

Data sources A search was conducted using three online databases (MEDLINE, CINAHL and PsycINFO).

Eligibility criteria Fifteen studies met the inclusion criteria: primary qualitative research involving carers of people with dementia who had been involved in making proxy healthcare decisions.

Data extraction and synthesis Two independent researchers conducted validity assessments for each paper selected for inclusion, and discrepancies were resolved by discussions with a third reviewer. Nvivo software was used and conceptual findings from study papers lead to interpretations of findings by the team. Results From the 15 papers included in the study, three main domains arose from the meta-ethnography; informational, practical and emotional. Informational support needs included information about dementia itself and the anticipated disease trajectory. Practical needs included continuity of care, person-centred care and the use of legal frameworks.

Emotional support included recognising the guilt that healthcare decisions can provoke and the importance of providing guidance in an empathic manner.

Conclusions This meta-ethnography highlights opportunities for healthcare professionals and policymakers to improve experiences of carers making proxy healthcare decisions for people with dementia. PROSPERO registration number CRD42020124485.
Strengths and limitations of this study

- To our knowledge, this is the first systematic review to focus on the experience of proxy healthcare decision-making for carers of people with dementia.

- By translating results of multiple studies, we make the results more readily available to practitioners, policymakers and researchers.

- Although there was a comprehensive search strategy with inclusion of international papers, the study did not include non-English-language publications.

- Studies may also have been missed due to the variety of terminology used in this field.

\section{INTRODUCTION}

Dementia affects an estimated 50 million people worldwide with 850000 sufferers in the UK. As the UK population ages and deaths from other causes are avoided due to improvements in prevention and treatment, dementia prevalence is likely to rise. The number living with dementia in the UK is expected to almost double to 1.6 million in the next 10 years. ${ }^{1}$ Dementia is the leading cause of death in the UK, ${ }^{2}$ but the disease often runs a protracted course over many years, and most people affected will have other significant health problems. Over $90 \%$ of dementia sufferers have at least one comorbidity. ${ }^{1}$ Approximately, 700000 people in the UK provide informal care for someone with dementia. It is a particular difficult and stressful condition to care for. ${ }^{3}$

Decisions frequently need to be made about the healthcare of people with dementia. These range from decisions to undergo testing to commencing or continuing treatment for dementia or for other conditions. Dementia can be worsened by the disruption to routine and changes to physical health that may result from healthcare decisions. 
This must be balanced against the potential gain from accepting care making these decisions complex. Carers are often required to be involved in proxy decisionmaking about healthcare as an individual's capacity to make decisions declines.

Shared decision-making is a key feature of personalised care, which forms part of the National Health Service (NHS) long-term plan. ${ }^{4}$ Shared decision-making ensures that individuals are supported to make decisions that are right for them. It is a collaborative process through which a clinician supports a patient to reach a decision about their treatment. The conversation brings together: the clinician's expertise, such as treatment options, evidence, risks and benefits and what the patient knows best: their preferences, personal circumstances, goals, values and beliefs. Shared decision-making is known to lead to more realistic expectations, a better match between individuals' values and treatment choices and fewer unnecessary interventions. ${ }^{5}$ The NHS long-term plan states that personalised care will underpin care for people with dementia. ${ }^{4}$ Understanding the support needs of carers acting as proxy decision-makers will be vital if people with dementia who have lost decision-making capacity, and their carers are to benefit from the move towards shared decision-making.

The rationale for this systematic review and metaethnography of qualitative studies were to review the existing literature with a view to developing new understanding of the support needs of carers for people with dementia facing healthcare decisions and to inform practitioners who may be in a position to provide support. Most published research on making decisions by proxy for people with dementia has focused on end of life care $^{67}$ and nursing home placement. ${ }^{8-10}$ Decision-making about healthcare for comorbidities earlier in the disease trajectory has been less well studied.

\section{Research objectives}

- Describe family carer experiences of proxy decisionmaking about healthcare treatment for a relative with dementia, excluding decisions about end of life care.

- Identify barriers and facilitators family carers experience when making proxy decisions about healthcare treatment for a relative with dementia.

\section{METHOD}

\section{Patient and public involvement}

Patient and public involvement (PPI) work was conducted with a dementia-specific PPI group based at the University of Sheffield. This shaped an initial scoping literature review and development of the research question.

\section{Eligibility criteria}

Inclusion criteria:

a. People of any age and gender who have a close relative with dementia (regardless of where they reside).

b. Proxy decision-making about a healthcare treatment c. Any primary, empirical research; qualitative, mixed methods

Exclusion criteria:

a. Published prior to 1995

b. Non-English language

c. Only report proxy decisions not related to healthcare

d. End of life

e. Reviews, editorials, dissertations, meeting abstracts and correspondence

\section{Information sources}

We searched MEDLINE, PsycINFO and CINAHL. Searches were limited by date from 1 January 1995 to 1 May 2020. Searches were restricted to English language. Searches were repeated on the 22 June 2021.

\section{Search strategy and selection criteria}

The objective of this study was to review the existing literature on the support needs of carers acting as proxy healthcare decision-makers for people with dementia. The protocol for this systematic review was published in the international prospective register of systematic reviews on 5 June 2020. https:/ / www.crd.york.ac.uk/PROSPERO

Qualitative studies that clearly reported qualitative findings were eligible for inclusion if they discussed proxy healthcare decision-making.

Target searches using Boolean operators combined terms and Medical Subject Headings related to

- carer or caregiver or informal carer or family carer or relative AND

- Decision making or Proxy or Decide or Surrogate decision mak* or 3rd party decision mak* AND

- dementia or Alzheimer's AND

- Qualitative

Study selection

Studies were excluded if they focused entirely on decisions about nursing or home placement, or end of life care and the steps of study selection are represented in the Preferred Reporting Items for Systematic reviews and Meta-Analyses (PRISMA) diagram (figure 1).

\section{Quality appraisal}

The qualitative version of the Critical Appraisal Skill Programme (CASP) (Critical Appraisal Skills Programme, 2018) ${ }^{11}$ was used to assess methodological quality of the included studies by VJH with a sample of papers also being assessed by SL. Discrepancies were resolved by discussion. Quality ratings informed data synthesis and were not used as exclusion criteria. The CASP was also used to reduce the risk of reporting bias, and discussions of the validity of each study were done during data extraction and synthesis.

\section{Data Extraction}

Key features of each study were extracted by VJH and independently checked by SL and CM. For each study, the followings were extracted: author, year of publication, country of origin, stated aim, participant characteristics, 

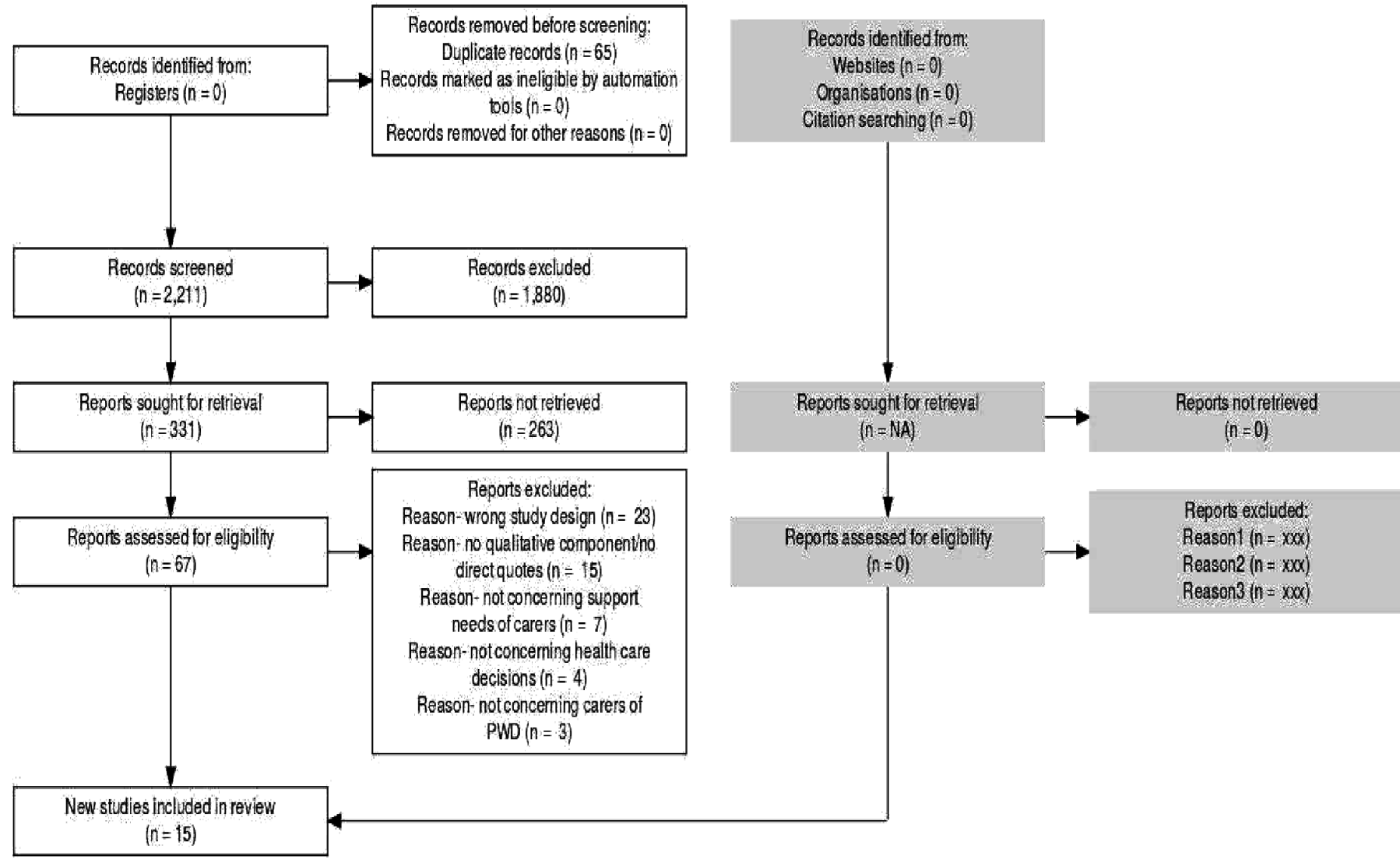

Figure 1 Preferred Reporting Items for Systematic reviews and Meta-Analysis diagram.

method of data collection, qualitative methodology and analytical approach. The outcomes that were sought in the papers are summarised in table 1 , and these features are found in table 2.

We followed Noblit and Hare's seven steps of metaethnography. ${ }^{12}$ In a meta-ethnographic analysis, information is classified as a first, second and third-order constructs. First-order constructs are direct quotes within studies, second-order constructs are authors' interpretations within the primary studies, third-order constructs

\begin{tabular}{|c|c|}
\hline Sample & $\begin{array}{l}\text { People of any age and gender who have a } \\
\text { close relative with dementia (regardless of } \\
\text { where they reside) }\end{array}$ \\
\hline $\begin{array}{l}\text { Phenomenon of } \\
\text { interest }\end{array}$ & $\begin{array}{l}\text { Proxy decision-making about a healthcare } \\
\text { treatment }\end{array}$ \\
\hline Design & Any qualitative primary, empirical research \\
\hline $\begin{array}{l}\text { Evaluation } \\
\text { (outcomes) }\end{array}$ & $\begin{array}{l}\text { Experiences, support needs, barriers, } \\
\text { facilitators of family/informal carers making } \\
\text { proxy decisions about healthcare treatment for } \\
\text { a relative with dementia }\end{array}$ \\
\hline
\end{tabular}

PICO, Population, intervention, comparison, outcome. are interpretations synthesised by the reviewers from second-order constructs.

$\mathrm{VJH}$ and SL read each paper repeatedly to familiarise themselves before performing line-by-line coding of all first and second-order constructs from the results and discussion sections of each paper. The research team met regularly throughout the review process to discuss the first and second-order constructs. These were clustered into candidate third-order constructs. The next stage of the meta-ethnography was to translate the studies into each other. This was done by focusing on each candidate thirdorder construct in turn and compiling lists of first and second-order constructs that related to it, where candidate's third-order constructs were not robustly supported by the data they were rejected. A process of constant comparison between papers was conducted, leading to the development of concise statements for each construct (synthesising translations). Both contradictory and directly comparable findings were considered together to develop a line of argument synthesis. An example of how this was applied in this study is seen in table 3 .

\section{Bias assessment}

Two independent researchers conducted validity assessments for each paper selected for inclusion and 


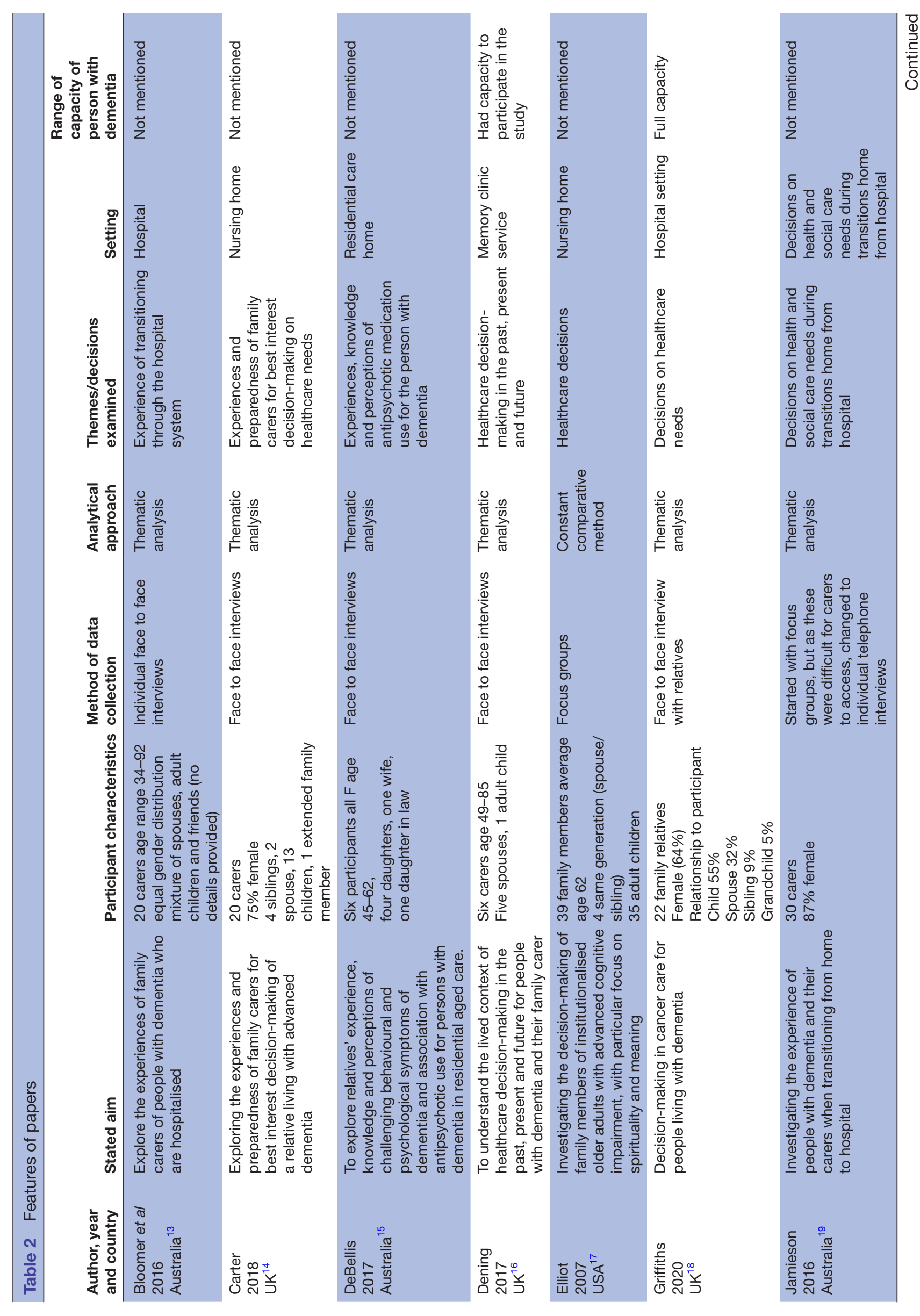




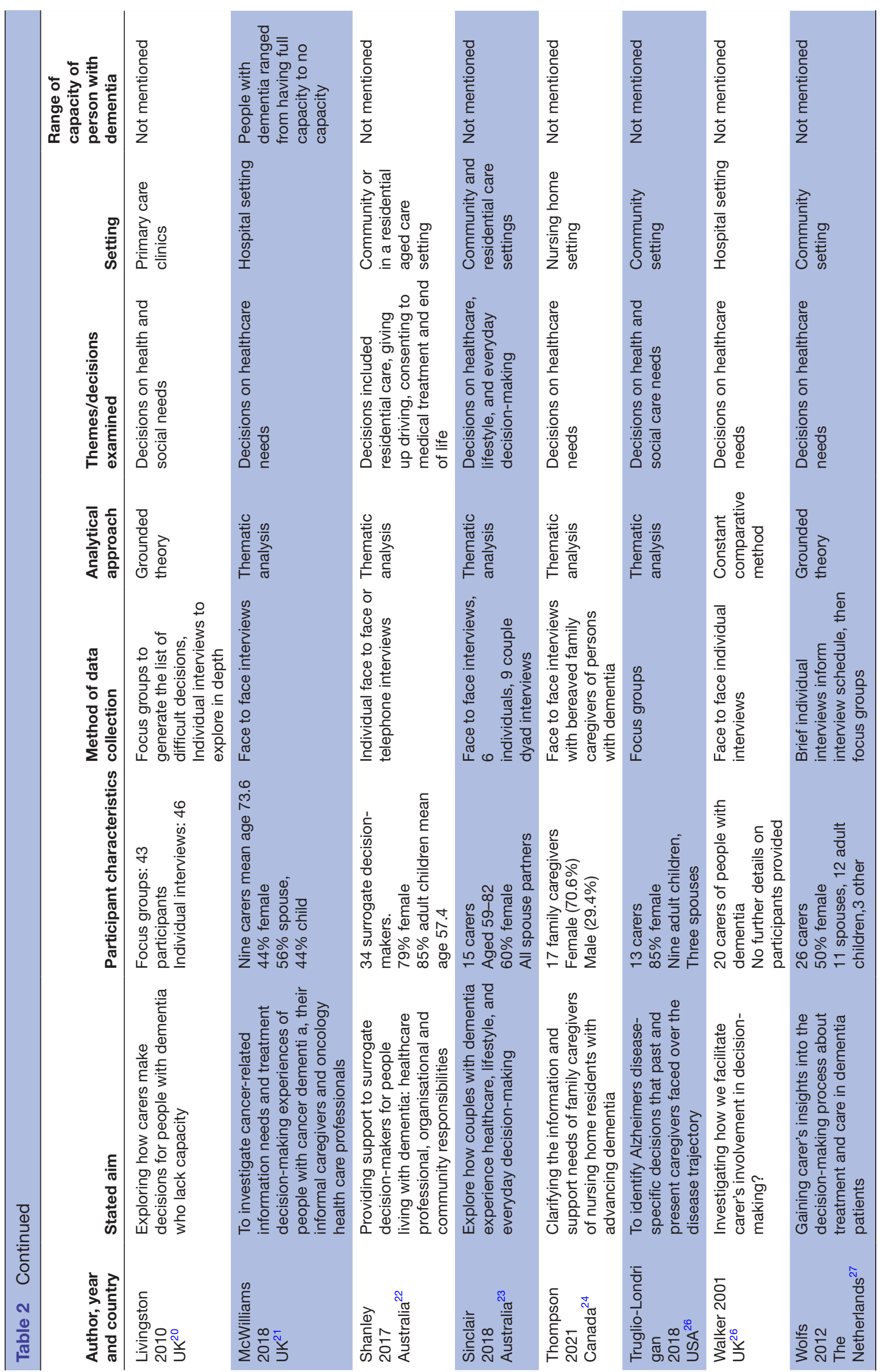




\begin{tabular}{|c|c|c|}
\hline Construct & Explanation & Example \\
\hline $\begin{array}{l}\text { First-order } \\
\text { constructs }\end{array}$ & $\begin{array}{l}\text { Carers accounts of } \\
\text { their experiences }\end{array}$ & $\begin{array}{l}\text { 'it's a lot of negotiation... sometimes...it's a case of having a familiar face' } \\
\text { I think, you know, when he was initially diagnosed, it would have been great to have } \\
\text { somebody from that point onwards that you could have dealt with like one single person } \\
\text { or one single number that you could call and say, "This is happening now. What typically } \\
\text { happens here? } \\
\text { You know, what, what is a good decision to make here?". .. So yeah it just would have } \\
\text { been good to, to, I suppose just to have some sort of advocacy [Right] for the families jus } \\
\text { so that you can make informed decisions. }\end{array}$ \\
\hline $\begin{array}{l}\text { Second-order } \\
\text { constructs }\end{array}$ & $\begin{array}{l}\text { Author's views } \\
\text { and interpretations } \\
\text { expressed as } \\
\text { themes in the } \\
\text { primary papers }\end{array}$ & $\begin{array}{l}\text { Similarly, healthcare professionals unfamiliar with the family and the resident's individual } \\
\text { wishes were also noted to cause unnecessary anxiety, again resulting in reluctance of } \\
\text { further contact. } \\
\text { The experience of an uncoordinated discharge process was for family and friends } \\
\text { compounded by their own exhaustion after their hospital vigil. The tiredness was further } \\
\text { complicated by delays in restarting community services that were accessed previously } \\
\text { This health professional was often their general practioner (GP). Having this consistent, } \\
\text { ongoing support helped the surrogate decision- maker become aware of issues and } \\
\text { find their way through the complex maze of service provision. It meant that surrogate } \\
\text { decision- makers did not have to keep repeating their story and building trust with new } \\
\text { professionals. }\end{array}$ \\
\hline $\begin{array}{l}\text { Third-order } \\
\text { constructs }\end{array}$ & $\begin{array}{l}\text { The views and } \\
\text { interpretations of } \\
\text { the synthesis team }\end{array}$ & $\begin{array}{l}\text { Continuity of care } \\
\text { Having a trusted health or social care professional who understood both the patient and } \\
\text { the healthcare system was hugely valued by carers. }\end{array}$ \\
\hline
\end{tabular}

discrepancies were resolved by discussions with a third reviewer. Nvivo software was used and conceptual findings from study papers lead to interpretations of findings by the team. A thorough CASP for qualitative studies was done to reduce for other biases (see table 4).

\section{RESULTS}

\section{Literature search results}

The initial and updated searches combined identified 2276 records from the original database searches. After removing duplicates, initial screening of abstracts and titles, and 67 full texts were further assessed for inclusion. At this stage, 52 full texts were excluded, leaving 15 papers for inclusion in the review. ${ }^{13-27}$

Out of 15 studies, 5 were conducted in Australia, 6 in the UK, 2 in the USA, 1 in Canada and 1 in the Netherlands. Nine collected data through interviews only, two used focus groups only, two used a combination of focus groups and individual interviews. One of the studies that used interviews had intended to use focus groups but changed data collection methodology due to difficulty recruiting to focus groups. In total, the included participants across all studies were 366 . There was marked variation between the levels of information presented about participants. For studies where the information was available, $69 \%$ of participants were women and the majority were either spouses/partners or adult children of the person with dementia. Only three studies (Griffiths, Livingston and Thompson) provided data on ethnicity or deprivation. The lack of discussion of diversity in the other studies may indicate that this had either not been sufficiently considered or achieved.

\section{Quality of reporting}

CASP ratings ranged from 6 to 10 out of 10 , indicating general moderate to high levels of quality in reporting qualitative research. The median of the ratings was 9 , with most studies omitting to report reflection on the relationship between the researcher and the participant.

\section{Synthesis}

An illustration of how constructs were developed is provided in table 2. Support needs of carers making proxy healthcare decisions for people with dementia fell into three main domains; informational support, practical support and emotional support. Third-order constructs within this synthesis are illustrated using example of firstorder constructs from the original papers.

\section{Domain 1}

\section{Informational support needs}

Carers needed a number of pieces of information to be able to make proxy decisions. This domain captures support needs regarding information on dementia itself as well as details of the healthcare decision being faced.

\section{Awareness of dementia and disease trajectory}

In order to be able to make confident and informed decisions for their loved ones, carers require a sound understanding of dementia, especially with regards to the disease trajectory. An absence of this understanding was a recurring theme in many of the included studies. The reality of inevitable cognitive decline and loss of capacity only became apparent to many participants as they lived through it. 


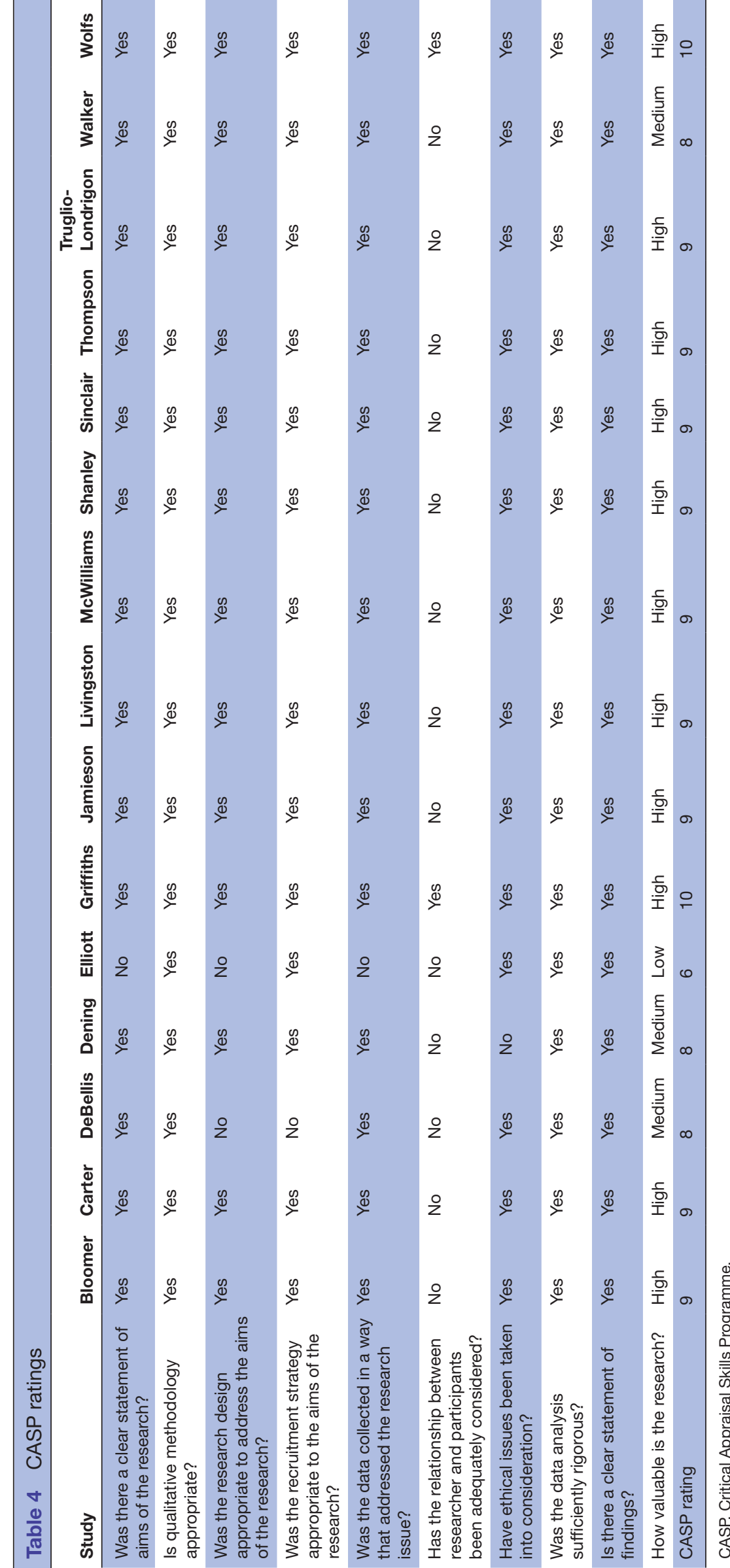

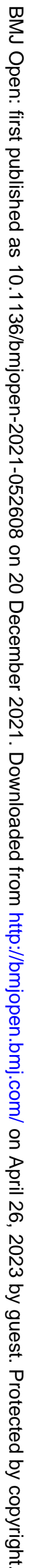


We didn't realise what dementia meant, the implications... I think that people who are carers should receive some training... told what to expect and what to do, before it happens, not when it happens-Livingston.

\section{Information about the individual decision to be made Information content}

Shared decision-making requires individuals to have sufficient information about the options available and the evidence, risks, benefits for these. In reality, carers described making decisions with incomplete information.

They didn't say it like it were...we thought there would be one or two [side effects], but I didn't think they'd be as severe as they were-McWilliams

It's also hard to know at each step, is it happening because of the disease or is she medicated? I don't know-Debellis

\section{Information delivery}

Carers were usually keen to involve the person with dementia as much as possible in decision-making. In order to achieve that, information needed to be delivered at a slower than normal pace, and carers often went to efforts to translate the information into a more understandable form.

It's really fast for me... all I could think was well if I wasn't there and you [patient] wouldn't have remembered...for somebody with dementia it needs to be slowed down-McWilliams

In reality, the person with dementia was not usually able to make healthcare decisions due to their complex nature, but the intention to involve them remained important.

We start off as a joint thing to talk about what needs deciding but normally [it] ends up with me making the final [decision]-Sinclair

\section{Signposting}

Carers often sought informational support from sources other than the healthcare professional. Other carers with experience of making similar decisions were particularly useful.

I've got an online specialist frontotemporal dementia support forum which is an international forum which consists entirely of other carers and other patients and it's a very knowledgeable forum very well organised very well moderated. And I wish I'd found it 2 years earlier-Shanley

Appropriate signposting to these services can help carers to feel supported with healthcare decisions.

\section{Practical support needs}

This domain focuses on the practicalities surrounding healthcare decisions. It deals with how services can be organised to provide better support for carers. It also considers legal support structures.

Continuity of care

Having a trusted health or social care professional who understood both the patient and the healthcare system was hugely valued by carers.

'We have a lot of faith in our case manager. He knows the entire dementia network and whatever question or needs we have, he takes care of it-Wolfs

Many carers had not experienced continuity of care but recognised how valuable it could have been when faced with healthcare decisions.

when he was initially diagnosed, it would have been great to have somebody from that point onwards that you could have dealt with like one single person or one single number that you could call and say, "This is happening now. What typically happens here? You know, what, what is a good decision to make here?" ... So yeah it just would have been good to, to, I suppose just to have some sort of advocacy for the families just so that you can make informed decisions-Shanley

\section{Person-centred care}

Carers become experts in the person with dementia as an individual. They act as advocates and their input into healthcare decisions is essential to achieve true person centred care.

Carers' expertise in their loved one's condition and knowledge of their preferences was routinely overlooked or dismissed by healthcare staff. This left carers feeling disempowered and frustrated.

there was never any communication with me, when I did try to say something they just ignored me and listened to him-Jamieson

\section{Early planning and legal context}

Proxy healthcare decisions are easier to make when carers have a clear knowledge of the person with dementia's wishes. Encouraging families to have these discussions early in the disease trajectory while the person with dementia has capacity to do so facilitates future healthcare decision-making.

Yes, it was very, very difficult. And in hindsight, it would have been a wonderful thing to have had them [conversations] but we didn't-Shanley

These conversations are difficult and some individuals and families need a lot of support with them. Explanation of the potential benefits for carers when they are faced with healthcare decisions in the future may help some individuals to address this.

we tried to talk to mummy about what care she would like further down the line, but she never discuss it... she just wouldn't get into that conversation... and I 
suppose just when we had to start making those decisions mummy was beyond having any input really in it-Carter

The studies were conducted in a range of countries. Each of the included countries have legal provisions, which allow individuals to formally nominate one or more individuals to act on their behalf should they lack capacity in the future. In the UK, this is known as lasting power of attorney (LPA). The studies in this review showed that some participants were aware of the existence of these legal frameworks. A minority had put them in place. Commonly, carers and people with dementia were resistant to making LPAs.

...I didn't say not at all... I wouldn't do it until much later on I think... I see it as something you hand over when its necessary, not before...-Dening

The mistaken belief that there would be opportunity to set up LPAs once dementia was more advanced led to many reaching a situation where the opportunity was lost.

The only thing that could happen now is Court of Protection... because my wife can't sign-Livingston

One technique that some families used to encourage the person with dementia to make an LPA was to make them for other family members at the same time. This allowed it to be framed as a generic safeguard in case of future eventualities rather than an individual decision necessitated by their inevitable loss of capacity.

if we did [lasting power of attorney] for both of them [parents], it wouldn't feel like it was just for my mum because she's dementing-Livingston

\section{Emotional support}

This domain focuses on the emotional impact of making healthcare decisions by proxy and how carers can be supported with this.

\section{Guilt}

Making proxy healthcare decisions can be an emotionally fraught process. Healthcare professionals need to be mindful of the impact that decision-making can have on carers. Checking in with carers about the emotional burden and where necessary signposting to services is important.

But for a time there, I did feel like I was in charge of ending my mother's life. And I think, if I hadn't had the psychologist to talk that through, I would have found that really difficult, really difficult-Shanley

The burden of guilt was particularly difficult to manage when carers had to make decisions alone or in conflict with family members.

My brother and sister... wanted the drip, antibiotics and the oxygen reinstated... and the doctor said 'it will flood her heart' and she died a horrific death... but my brother always said, 'oh where there's hope'... There was no hope-Livingston

Where decisions were shared, it significantly alleviated the guilt.

My case manager explains what options there are and what they mean, and I make the decision together with my mother and my sisters. If you work as a team, you make the best choices-Wolfs

\section{Empathic guidance}

When facing proxy decisions, carers appreciated guidance from healthcare professionals. It was important, however, that those decisions were not made unilaterally by professionals.

Recognition and consideration of the needs and concerns of the person with dementia and the carer were key. This approach is described variously in the included papers, but one paper (Shanley) uses the elegant-term empathic guidance.

And, and I think that was, it was very, it was really helpful to have the medical staff kind of put it in, you know, they didn't beat around the bush... I really felt like they were very supportive and they were looking out for her, and they were looking out for me as well. And so I kind of, I did put a lot of trust in what they said... And they were actually considering her needs at the time and, and so they helped me make that decision-Shanley

Where healthcare professionals did not act as empathic guides and failed to demonstrate consideration of the needs of all parties, attempts to engage carers in decisionmaking were often superficial and unsatisfactory.

The hospital was no help, and I got aggravated with all of them and finally I had to call a meeting between all the doctors because I could not get anyone to give me any answers-Truglio Londrigon

\section{DISCUSSION}

\section{Summary of main findings}

In order to make healthcare decisions for people with dementia, carers require an understanding of the dementia itself and the likely disease trajectory. They also need information about the decision to be made, presented in a form that can be understood and that can be shared with the person with dementia wherever possible.

Carers may be facilitated in decision-making by access to support groups, especially with carers who have faced similar decisions.

Preparation for future healthcare decision-making should be facilitated early in the dementia trajectory, so that carers feel more confident about the person with dementia's wishes and so that decisions truly are made 
in their best interests. Healthcare professionals should encourage families to formalise arrangements for future decision-making using the relevant legal structures such as LPAs.

Professionals who recognise the emotional burden of decision-making and act as empathic guides for carers, making that proxy healthcare decisions are highly valued.

\section{Strengths and limitations of the study}

This systematic review is novel in that it explores proxy healthcare decision-making at earlier stages of the disease trajectory for people with dementia, rather than focusing on end of life care or care home placement decisionmaking. We applied rigorous quality assurance to each study and identified strengths and gaps in the evidence base as well as synthesising key themes of relevance to practice and policy. We have been guided by the report from eMERGe (The Meta-ethnography reporting guidance), which says there are ' no bespoke reporting guidance exists for meta-ethnography... Existing generic guidance for reporting qualitative evidence synthesis pays insufficient attention to reporting the complex synthesis processes of meta-ethnography'. ${ }^{28}$ With this in mind, we have used the PRISMA checklist for both abstract and article paper in ensuring there was good practice and rigorous, comprehensive analysis, interpretation and synthesis of the evidence.

A systematic review is by its nature dependent on the quality of the original studies. Of the 15 studies in this review, only one (Livingston) provided detailed demographic data on participants. This study recruited a diverse population in terms of ethnicity, educational background, age and gender. The lack of demographic information in the other studies may suggest a lack of diversity, but certainly suggests a lack of consideration of diversity by the authors. The studies were all conducted in English and excluded the voices of people for whom English is not their first language.

The goal of this review was to focus on the support needs of carers making proxy healthcare decisions for people with dementia. Few of the included papers focused entirely on healthcare decisions from a carer perspective; many dealt with a range of decision types, others included views of other parties such as the person with dementia or the healthcare professional. As a result, there were often only small sections of the included papers, which yielded relevant quotes.

The thematic synthesis was conducted by four academic general practitioners; VJH, CM, CH and SL. While every effort was made to maintain a reflexive approach, there will undoubtedly have been shared assumptions and blind spots, which could have been mitigated with a more diverse research team.

\section{Comparison with existing literature information and knowledge} about dementia

A lack of knowledge about dementia and the disease trajectory was a common theme throughout this review.
A recent systematic review of the public's knowledge and understanding of Alzheimer's disease and dementia found that there was a common misconception that dementia was a normal part of ageing. ${ }^{29}$ Carers described a need for a postdiagnosis training programme to teach them what to expect. Key within this was the importance of early advanced care planning. Many participants missed the opportunity to have advanced care planning discussions with their loved ones, in part because they did not realise the inevitable downward trajectory of dementia with resultant loss of capacity. Proxy healthcare decisions were much easier to make and accept when carers had a clear understanding of their relative's wishes. Supporting carers and people with dementia to have those conversations early facilitates proxy decision-making later on.

\section{Shared decision-making}

Shared decision-making is a key component of the NHS long-term plan. ${ }^{4}$ It is widely accepted that shared decisionmaking facilitates patients to make decisions that are best for them. A 2011 report by The King's Fund ${ }^{5}$ states at the heart of decision-making is the recognition that clinicians and patients bring different but equally important forms of expertise to the decision-making process'. In the context of proxy decision-making, the carer should take the role of the second expert; however, our review suggests that their expertise is commonly disregarded.

These findings echo the Care Quality Commission's 2016 review of how people are involved in their care, which found limited understanding, recording and monitoring of people's wishes and preferences, inadequate family and carer involvement and insufficient information and explanation of care and support options. ${ }^{30}$ Some of the barriers to the implementation of shared decision-making identified in the literature include practical factors such as a lack of continuity of care and time constraints. Additionally, the challenges involved in building good rapport between both parties have been identified ${ }^{31}$ Some professional groups have proposed solutions such as templates that can be used at various levels of service delivery, ${ }^{32}$ while other authors argue that more research is still needed in the area of shared decision-making in primary care in order to better conceptualise the barriers and solutions. ${ }^{33}$

\section{Continuity of care}

Many studies have shown the benefits of continuity of care both in terms of patient experience and clinical outcomes. ${ }^{34-37}$ The 2018 National Institute for Health and Care Excellence (NICE) dementia guidelines recommend that people living with dementia be provided with a single-named health or social care professional who is responsible for coordinating their care and that a programme of postdiagnostic support be offered to carers. ${ }^{38}$ In practice, delivery of this support is inconsistent across the UK, with multiple sectors delivering a range of services with the potential for duplication or gaps. ${ }^{39}$ Our review found similarly inconsistent access to care coordination, but where it was available, carers valued it. 


\section{Digital signposting}

The emotional burden of decision-making for a person with dementia can be enormous. One of the many consequences of the COVID-19 pandemic is the loss of in person support and support networks. ${ }^{40}$ Increasing use of online support forums offers an alternative for some, but $29 \%$ of people aged over 65 in the UK have never used the internet. ${ }^{41}$ The movement of services online that has been hugely accelerated by the pandemic risks leaving those without internet access or skills unable to access a wealth of informational, practical and emotional support options.

\section{Implications for future research and clinical practice}

The NHS aspires towards making person-centred care, including shared decision-making, part of routine practice. Research is needed to establish how we can achieve this meaningfully for proxy decision-makers, so that both they and the person with dementia have access to the benefits of person-centred care. Patients with dementia suffer from inevitable decline in cognition and most will reach a point where they are unable to make healthcare decisions independently. If people with dementia are to benefit from the drive towards patient-centred care, it is vital that we consider the support needs of their carers.

Continuity of care can be difficult to achieve in the modern health system but has undoubted benefits for patients with complex comorbidity. ${ }^{42}$ Commissioners should consider how continuity can best be achieved. It should be clear to practitioners and service users who that single point of contact is and how to access necessary support.

In an increasingly digital world, there is a potential for widening health inequalities by reducing access to services for those who do not have internet access or computer literacy. A significant minority of older adults does not use the internet, and policymakers and commissioners must take measures to ensure that services remain accessible to all, while also providing opportunities for people to improve their digital literacy.

\section{Twitter Caroline Mitchell @dclovesGP}

Acknowledgements The authors would like to thank Anthea Tucker for help with search strategies and Professor Christopher Burton for advice on the manuscript.

Contributors Conception or design of the work: $\mathrm{CH}, \mathrm{CM}$ and VH. Data collection: $\mathrm{VH}$ and SL. Data analysis and interpretation: VH, SL and CM. Drafting the article: VH and $\mathrm{CM}$. Critical revision of the article: VH, SL and CM. Final approval of the version to be published: all authors. Guarantor: CM

Funding This work was supported by The RCGP Scientific Foundation Board, grant number SFB2018-07.

Competing interests None declared.

Patient consent for publication Not applicable.

Ethics approval This study does not involve human participants.

Provenance and peer review Not commissioned; externally peer reviewed.

Data availability statement All data relevant to the study are included in the article or uploaded as supplementary information. No additional data are available

Supplemental material This content has been supplied by the author(s). It has not been vetted by BMJ Publishing Group Limited (BMJ) and may not have been peer-reviewed. Any opinions or recommendations discussed are solely those of the author(s) and are not endorsed by BMJ. BMJ disclaims all liability and responsibility arising from any reliance placed on the content. Where the content includes any translated material, BMJ does not warrant the accuracy and reliability of the translations (including but not limited to local regulations, clinical guidelines, terminology, drug names and drug dosages), and is not responsible for any error and/or omissions arising from translation and adaptation or otherwise.

Open access This is an open access article distributed in accordance with the Creative Commons Attribution Non Commercial (CC BY-NC 4.0) license, which permits others to distribute, remix, adapt, build upon this work non-commercially, and license their derivative works on different terms, provided the original work is properly cited, appropriate credit is given, any changes made indicated, and the use is non-commercial. See: http://creativecommons.org/licenses/by-nc/4.0/.

\section{ORCID iDs}

Victoria Hodges http://orcid.org/0000-0002-4765-3848

Caroline Mitchell http://orcid.org/0000-0002-4790-0095

\section{REFERENCES}

1 Alzheimers Research UK. Alzheimers Research UK; c2021. Available: https://www.dementiastatistics.org/statistics-aboutdementia/ prevalence/dementiastatistics.org [Accessed 26 Jan 2021].

2 Office for national statistics [internet]. Office for national statistics [internet]: Leading causes of death UK: 2001-2018. Available: https://www.ons.gov.uk/peoplepopulationandcommunity/ healthandsocialcare/causesofdeath/articles/leadingcausesofd eathuk/2001to2018\#: :text=1.,12.7\%25\%20of\%20all\%20deaths\% 20registered [Accessed 19 Dec 2020].

3 Ory MG, Hoffman RR, Yee JL, et al. Prevalence and impact of caregiving: a detailed comparison between dementia and nondementia caregivers. Gerontologist 1999;39:177-86.

4 NHS England [Internet]. NHS England [Internet]: Universa Personalised Care. Available: https://www.england.nhs.uk/wpcontent/uploads/2019/01/universal-personalised-care.pdf [Accessed 26 Jan 2021].

5 Coulter A, Collins A. Making Shared Decision Making a Reality. The Kings Fund 2011 [Internet]. Available: https://www.kingsfund.org.uk/ sites/default/files/Making-shared-decision-making-a-reality-paperAngela-Coulter-Alf-Collins-July-2011_0.pdf [Accessed 26 Jan 2021].

6 Xie B, Berkley AS, Kwak J, et al. End-of-life decision making by family caregivers of persons with advanced dementia: a literature review of decision AIDS. SAGE Open Med 2018;6:1-9.

7 Sellars M, Chung O, Nolte L, et al. Perspectives of people with dementia and carers on advance care planning and end-of-life care: a systematic review and thematic synthesis of qualitative studies. Palliat Med 2019;33:274-90.

8 Taghizadeh Larsson A, Österholm JH. How are decisions on care services for people with dementia made and experienced? A systematic review and qualitative synthesis of recent empirical findings. Int Psychogeriatr 2014;26:1849-62.

9 Donnelly N-A, Hickey A, Burns A, et al. Systematic review and meta-analysis of the impact of carer stress on subsequent institutionalisation of community-dwelling older people. PLoS One 2015;10:e0128213.

10 Pritty B, De Boos D, Moghaddam N. Factors influencing the transition experience of carers for persons with dementia, when the person with dementia moves into residential care: systematic review and meta-synthesis. Aging Ment Health 2020;24:1371-80.

11 Public Health Resource Unit. Critical Appraisal Skills Programme (CASP), 2006. Available: http://www.casp-uk.net/\#!casp-toolschecklists/c18f8 [Accessed 3 Nov 2020].

12 Noblit GW, Hare RD. Meta-ethnography: synthesizing qualitative studies. vol. 11. California: Sage Publications, 1988.

13 Bloomer M, Digby R, Tan H, et al. The experience of family carers of people with dementia who are hospitalised. Dementia 2016;15:1234-45.

14 Carter G, McLaughlin D, Kernohan WG, et al. The experiences and preparedness of family carers for best interest decision-making of a relative living with advanced dementia: a qualitative study. $J \mathrm{Adv}$ Nurs 2018;74:1595-604.

15 De Bellis A, Bradley A, Xiao S. Antipsychotic use for behaviours by persons with dementia in residential aged care: The relatives' perspectives'. Australian Journal of Advanced Nursing 2017;35:23-32.

16 Dening KH, King M, Jones L, et al. Healthcare decision-making: past present and future, in light of a diagnosis of dementia. Int $\mathrm{J}$ Palliat Nurs 2017;23:4-11. 
17 Elliott BA, Gessert CE, Peden-McAlpine C. Decision making by families of older adults with advanced cognitive impairment: spirituality and meaning. J Gerontol Nurs 2007;33:49-55.

18 Griffiths AW, Ashley L, Kelley R, et al. Decision-making in cancer care for people living with dementia. Psychooncology 2020;29:1347-54

19 Jamieson M, Grealish L, Brown J-A, et al. Carers: the navigators of the maze of care for people with dementia-A qualitative study. Dementia 2016;15:1112-23.

20 Livingston G, Leavey G, Manela M, et al. Making decisions for people with dementia who lack capacity: qualitative study of family carers in UK. BMJ 2010;341:c4184-4184.

21 McWilliams L, Farrell C, Keady J, et al. Cancer-related information needs and treatment decision-making experiences of people with dementia in England: a multiple perspective qualitative study. BMJ Open 2018;8:e020250.

22 Shanley C, Fetherstonhaugh D, McAuliffe L, et al. Providing support to surrogate decision-makers for people living with dementia: healthcare professional, organisational and community responsibilities. Health Soc Care Community 2017;25:1563-70.

23 Sinclair C, Gersbach K, Hogan M, et al. How couples with dementia experience healthcare, lifestyle, and everyday decision-making. Int Psychogeriatr 2018;30:1639-47.

24 Thompson G, Hack T, Rodger K, et al. Clarifying the information and support needs of family caregivers of nursing home residents with advancing dementia. Dementia 2021;20:1250-69.

25 Truglio-Londrigan M, Slyer JT. Caregiver decisions along the Alzheimer's disease trajectory. Geriatr Nurs 2019;40:257-63.

26 Walker E, Dewar BJ. How do we facilitate carers' involvement in decision making? J Adv Nurs 2001;34:329-37.

27 Wolfs CAG, de Vugt ME, Verkaaik M, et al. Rational decision-making about treatment and care in dementia: a contradiction in terms? Patient Educ Couns 2012;87:43-8.

28 France EF, Cunningham M, Ring N, et al. Improving reporting of meta-ethnography: the eMERGe reporting guidance. BMC Med Res Methodol 2019;19:25

29 Cahill S, Pierce M, Werner P, et al. A systematic review of the public's knowledge and understanding of Alzheimer's disease and dementia. Alzheimer Dis Assoc Disord 2015;29:255-75.

30 Bate P. Better care in my hands care quality Commission, 2016. Available: https://www.cqc.org.uk/sites/default/files/20160519_ Better_care_in_my_hands_FINAL.pdf
31 Abrams EM, Shaker M, Oppenheimer J. The challenges and opportunities for shared decision making highlighted by COVID-19, the Journal of allergy and clinical immunology. Practice 2020;8:2474-80.

32 Légaré F, Stacey D, Graham ID, et al. Advancing theories, models and measurement for an interprofessional approach to shared decision making in primary care: a study protocol. BMC Health Serv Res 2008;8:2.

33 Murray E, Charles C, Gafni A. Model to fit the context of general practice. Patient Educ Couns 2006;62:205-11.

34 Cabana MD, Jee SH. Does continuity of care improve patient outcomes? J Fam Pract 2004;53:974-80.

35 Pereira Gray DJ, Sidaway-Lee K, White E, et al. Continuity of care with doctors - a matter of life and death? A systematic review of continuity of care and mortality. BMJ Open 2018;8:E021161.

36 Baker R, Freeman GK, Haggerty JL, et al. Primary medical care continuity and patient mortality: a systematic review. British Journal of General Practice 2020;70:e600-11.

37 Barker I, Steventon A, Deeny SR. Association between continuity of care in general practice and hospital admissions for ambulatory care sensitive conditions: cross sectional study of routinely collected, person level data. BMJ 2016;356:84

38 National Institure for health and care excellence, dementia: assessment, management and support for people living with dementia and their carers, 2018. Available: www.nice.org.uk/ guidance/ng97/chapter/Recommendations\#supporting-carers [Accessed 26 Jan 2021].

39 Frost R, Walters K, Wilcock J, et al. Mapping post-diagnostic dementia care in England: an e-survey. J Integr Care 2020;29:22-36.

40 Saltzman LY, Hansel TC, Bordnick PS. Loneliness, isolation, and social support factors in post-COVID-19 mental health. Psychol Trauma 2020;12:S55-7.

41 Office for national statistics, Internet users, 2019. Available: www ons.gov.uk/businessindustryandtrade/itandinternetindustry/bulletins/ internetusers/2019 [Accessed 26 Jan 2021].

42 Hua M, Gong MN, Miltiades A, et al. Outcomes after rehospitalization at the same hospital or a different hospital following critical illness. Am J Respir Crit Care Med 2017;195:1486-93. 